\title{
Early development of spasticity following stroke: a prospective, observational trial
}

\author{
Jörg Wissel • Ludwig D. Schelosky • Jeffrey Scott • \\ Walter Christe $\cdot$ Jürgen H. Faiss $\cdot$ Jörg Mueller
}

Received: 16 October 2009/Revised: 5 January 2010/ Accepted: 11 January 2010/Published online: 6 February 2010

(C) The Author(s) 2010. This article is published with open access at Springerlink.com

\begin{abstract}
This study followed a cohort of 103 patients at median 6 days, 6 and 16 weeks after stroke and recorded muscle tone, pain, paresis, Barthel Index and quality of life score (EQ-5D) to identify risk-factors for development of spasticity. $24.5 \%$ of stroke victims developed an increase of muscle tone within 2 weeks after stroke. Patients with spasticity had significantly higher incidences of pain and nursing home placement and lower Barthel and EQ-5D scores than patients with normal muscle tone. Early predictive factors for presence of severe spasticity [modified Ashworth scale score (MAS) $\geq 3$ ] at final follow-up were moderate increase in muscle tone at baseline and/or first follow-up (MAS =2), low Barthel Index at baseline,
\end{abstract}

J. Wissel $(\bowtie) \cdot J$. Scott

Neurological Rehabilitation Hospital, Kliniken Beelitz GmbH, Paracelsusring 6a, 14547 Beelitz-Heilstätten, Germany

e-mail: wissel@rehaklinik-beelitz.de

L. D. Schelosky

Kantonsspital Münsterlingen, 8596 Münsterlingen, Switzerland

e-mail: ludwig.schelosky@stgag.ch

W. Christe

Klinik für Neurologie, Ernst von Bergmann Hospital,

Charlottenstrasse 72, 14467 Potsdam, Germany

e-mail: wchriste@klinikumevb.de

\section{J. H. Faiss}

Asklepios Fachkliniken Brandenburg GmbH,

Buchholzer Str. 21, 15755 Teupitz, Germany

e-mail: j.faiss@asklepios.com

J. Mueller

Department of Neurology, Vivantes Klinikum Spandau,

Berlin, Germany

e-mail: Joerg.Mueller@vivantes.de hemispasticity, involvement of more than two joints at first follow-up, and paresis at any assessment point. The study helps to identify patients at highest risk for permanent and severe spasticity, and advocates for early treatment in this group.

Keywords Acute cerebral infarction - Spasticity · Spasticity related pain · Barthel index · Quality of life

\section{Introduction}

Upper motor neuron lesions may raise positive and negative symptoms [21]. Beside brisk tendon reflexes, clonus, spasms, and dystonia, spasticity is one of the positive phenomena and results from impaired reflex function and changes in rheologic muscle properties like stiffness, fibrosis, and atrophy [5]. Contracture is determined by degenerative changes and an alteration in passive and contractile properties of the muscle and may potentiate spasticity [5, 8, 10]. Negative features of upper motor neuron lesions are loss of selective control of muscles and limb segments, weakness, and slowness of movement and are closely interconnected with spasticity [5, 14]. The functional changes in the affected limbs may cause pain, dependency, and decline in the quality of a patient's life and self esteem.

Despite the severe consequences and high frequency of upper motor neuron lesions, only a few studies have addressed the occurrence and temporal evolution of spasticity following stroke $[11,13,14,17,18]$. The present study follows a cohort of patients from the immediate days after stroke to assess frequency and development of spasticity and identifies risk-factors for development of poststroke spasticity. 


\section{Patients and methods}

The stroke units of the Potsdam and Teupitz hospitals are both located in the federal state of Brandenburg, Germany, and serve for approximately 450,000 inhabitants. They accept all acute stroke patients without any selection. From April 1st to June 30th, 2006, all consecutive stroke patients ( $n=103$ ) admitted to the hospitals were included in the study without selection (patient details see Table 1).

To minimize interrater variability all patients were assessed by the same physiotherapist (J.S.) at baseline and each follow-up. J.S. is a seasoned physiotherapist with more than 10 years full-time practice in stroke rehabilitation. He observed consistent examination conditions and distinguished between spastic, rigid, and dystonic increase of muscle tone. Patients had their initial examination within the first 2 weeks after admission in the hospital ward (baseline). After a median of 6 (first follow-up) and 16 (second follow-up) weeks, the patients were reinvestigated either in the neighbouring rehabilitation units (Beelitz and Potsdam, Brandenburg, Germany) or at the patient's private or nursing home (Fig. 1).

Prior to study entry informed consent was required, either given personally or by an authorized family member. The study was approved by the Brandenburg ethics committee.

\section{Assessments}

At each visit the muscle tone of the shoulder, elbow, wrist, hip, knee, and ankle of all affected extremities was quantified by J.S. with the modified Ashworth Scale (MAS) [2]. The authors are aware that MAS assessed only an epiphenomenon rather than the cause of the functional

Table 1 Patient details $(n=103)$

\begin{tabular}{lc}
\hline Mean age (years) & $69(35-96)$ \\
\hline Percentage of patients $\leq 60$ years & $25 \%$ \\
Female & $38 \%$ \\
Type of stroke & \\
Ischemia & $86 \%$ \\
Hemorrhage & $14 \%$ \\
Lesion site & \\
Supratentorial & $83 \%$ \\
Infratentorial & $15 \%$ \\
Combined & $2 \%$ \\
Affected side & \\
Left hemisphere & $44 \%$ \\
Right hemisphere & $56 \%$ \\
Neglect & $15 \%$ \\
Patients with re-infarction & $16 \%$ \\
\hline
\end{tabular}

condition, but the present study was oriented to the diagnostic and not to the functional testing of spasticity [4]. During the study, only one patient obtained an antispastic treatment of $10 \mathrm{mg}$ oral baclofen per day (first and second assessment, MAS 3 and 4, respectively). The other patients had no antispastic drugs.

Pain at rest and pain evoked by passive joint movement was assessed by the 11 point box test. The assessment referred to the total amount of pain experienced by the patient, subgroups (musculo-skeletal or neuropathic pain) were not differentiated. Oral analgesics (NSARs, opioids) were applied when necessary and continued throughout the study in all patients with pain. Paresis was rated as present or absent at baseline and quantitatively on a $0-3$ scale $(0=$ no, $1=$ mild, $2=$ moderate, $3=$ severe paresis). At second follow-up. J.S. also recorded deficits of sensation and neglect at baseline and second follow-up as present or absent.

Functional disability was assessed by the Barthel Index at baseline, first and second follow-up. The Barthel Index measures a person's performance in basic self care. The maximum score of 100 indicates independency $[12,16]$.

Quality of life was calculated by the EuroQoL EQ-5D at each follow-up. The EQ-5D questionnaire is a state of health measure and describes health condition in mobility, self care, usual activities, pain/discomfort, and anxiety/ depression, with three levels per attribute (possible range $0-100)$. A higher score indicates a better quality of life $[1,7]$.

\section{Statistical analysis}

All variables were analyzed with non-parametric methods. Changes from baseline were compared with follow-up visits using the Wilcoxon signed-rank test. Correlation of paresis with MAS score was calculated by the MannWhitney $U$ Test. The EQ-5D-index sum score was calculated for each patient as follows: $100-(10 \times$ [item $1+-$ item $2+$ item $3+$ item $4+$ item5 - 5]) according to Hinz et al. [7]. Kruskal-Wallis one-way analysis of variance (ANOVA) was performed with EQ-5D-index sum score as dependent variable and paresis, spasticity, and pain as independent variables.

\section{Results \\ Baseline}

Baseline assessment was performed median 6 days following stroke with a range of 1-14 days. Nine patients $(8.7 \%)$ with re-infarction and spasticity (median MAS $=2$ [1-3]) were identified at the baseline examination and were 
Fig. 1 Study population

\begin{tabular}{|c|c|c|}
\hline \multicolumn{2}{|c|}{103 stroke pts. assessed } & \\
\hline & & 9 pts. excluded with pre-existing spasticity \\
\hline \multicolumn{2}{|c|}{94 pts. included into the study } & \\
\hline \multicolumn{2}{|c|}{$\begin{array}{l}23 \text { pts. }(24.5 \%) \text { with increased } \\
\text { muscle tone }\end{array}$} & $\begin{array}{c}\text { Baseline examination } \\
\text { median } 6 \text { (range 1-14) days after stroke }\end{array}$ \\
\hline MAS 1 & 11 & \\
\hline MAS $1+$ & 4 & \\
\hline MAS 2 & 8 & \\
\hline & & $\begin{array}{c}8 \text { pts. died (MAS 0/1/2=6/1/1 pts., } \\
\text { respectively) }\end{array}$ \\
\hline \multicolumn{2}{|c|}{86 pts. at first follow up } & \\
\hline \multicolumn{2}{|c|}{23 pts. (26.7\%) with spasticity } & \multirow[b]{2}{*}{ median 6 (range 4-12) weeks after stroke } \\
\hline MAS 1 & 5 & \\
\hline MAS 1+ & 4 & \\
\hline MAS 2 & 6 & \\
\hline MAS 3 & 4 & \\
\hline \multirow[t]{2}{*}{ MAS 4} & 4 & \\
\hline & & 3 pts. died (MAS 0/1/3=1/1/1 pt., respectively) \\
\hline \multicolumn{2}{|c|}{83 pts. at second follow up } & \\
\hline \multicolumn{2}{|c|}{18 pts. $(21.7 \%)$ with spasticity } & Second follow up \\
\hline MAS 1 & 7 & median 16 (range 12-24) weeks after stroke \\
\hline MAS 2 & 3 & \\
\hline MAS 3 & 2 & \\
\hline MAS 4 & 6 & \\
\hline
\end{tabular}

excluded from further analysis to avoid interference with pre-existing spasticity (Fig. 1).

Among the remaining 94 patients, 23 (24.5\%) showed an increase of muscle tone in at least one joint (Fig. 2). The MAS scores are given in Fig. 1.

Twelve patients (13\%) had pain in the extremities affected by their stroke. Median pain severity was 5 (range 4-10). Pain in patients with raised muscle tone affected the arm in seven, the leg in two and both arm and leg in three patients, was present at rest in seven and evoked by passive stretch in five patients. Weakness was present in $65 \%$ of patients. $13 \%$ of them suffered from tetraparesis, $87 \%$ from hemiparesis.

Patients with increased muscle tone had a significantly lower Barthel Index (median 63.3, range 45-100) than patients without spasticity (median 80.6, range 45-100; $P=0.07)$. The median baseline EQ-5D-index sum score was 75 (range 40-100). ANOVA showed a significant effect of paresis, increase of muscle tone and pain on quality of life $(P=0.004)$. 


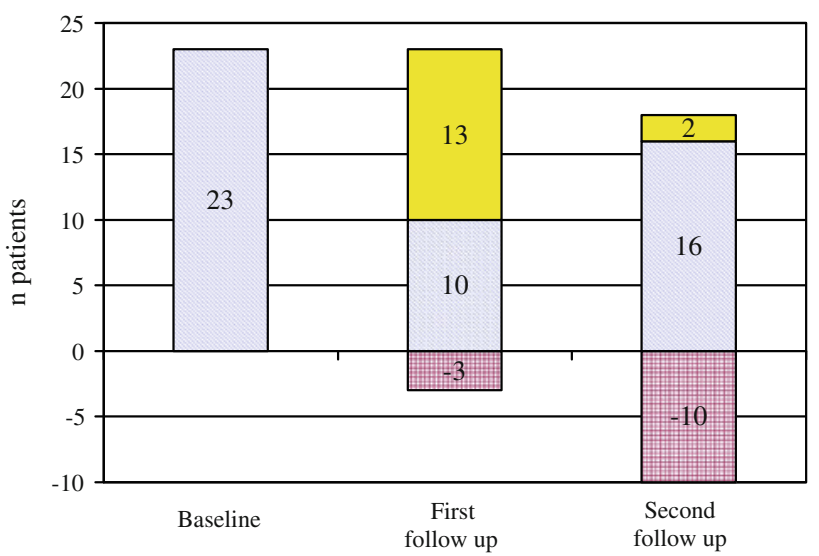

Fig. 2 Development of muscle hypertonia during follow-up. Number of patients with muscular hypertonia at different time points after stroke (blue fraction of the bar: patients with initial muscle hypertonia; red fraction of the bar: patients with initial hypertonia, but not at follow-up; yellow fraction of the bar: additional patients with muscle hypertonia)

\section{First follow-up}

The first follow-up assessment was performed median 6 weeks following stroke with a range of 4-12 weeks (Fig. 1). Eight of the 94 included patients have died since baseline (9\%). Twenty-three of the 86 surviving patients (26.7\%) showed a spastic increase of muscle tone in at least one joint (Fig. 2). If any spasticity occurred during the course of the study, it emerged in $98 \%$ of the patients up to the first follow-up. The MAS is given in Fig. 1.

Pain in extremities affected by stroke was present in eight of the 14 patients $(57 \%)$ with moderate (MAS $=2$ ) or severe spasticity (MAS $\geq 3$ ). Median Barthel Index was 90 (45-100).

\section{Second follow-up}

The second follow-up assessment was performed median 16 weeks following stroke with a range of 12-24 weeks. Three further patients had died since first follow-up (total of $11,12 \%$ ).

Eighteen of the 83 surviving patients at 4 month followup $(21.7 \%)$ showed an increase of muscle tone in at least one joint (Fig. 2). The MAS is shown in Fig. 1, the distribution of spasticity is depicted in Fig. 3. Spasticity developed most often in elbow, wrist, and ankle.

$17 \%$ ( $n=14)$ of all patients suffered from pain in extremities affected by their stroke. Median pain severity was 5 (range 4-8). Among patients without spasticity only one out of $65(1.5 \%)$ had pain while 13 of 18 stroke sufferers with spasticity $(72 \%)$ reported pain $(P<0.001)$ (Fig. 4). Pain evoked by passive stretch in extremities affected by stroke was present in 10 of the 11 patients

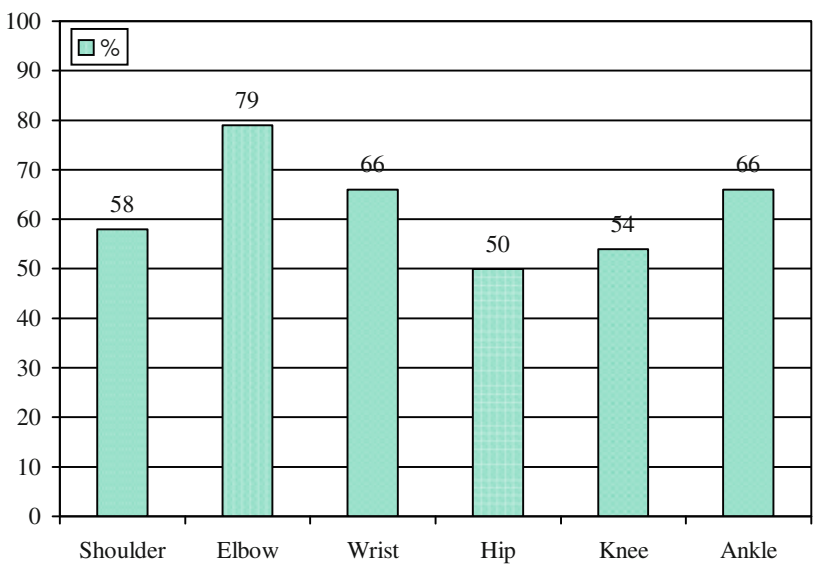

Fig. 3 Localisation of spasticity in stroke patients at second followup. Numbers indicate percent of patients with spasticity at the respective joint

$(91 \%)$ with moderate (MAS $=2)$ or severe spasticity (MAS $\geq 3$ ) and in three of seven patients (43\%) with mild spasticity (MAS $=1$ ). Spastic arm was painful in nine, spastic leg in two and spastic arm plus leg in two patients. Spasticity was associated with pain in the shoulder in $60 \%$, in the elbow in $100 \%$ and in the wrist in $33 \%$. Pain in the leg was not closely correlated to spasticity.

Weakness was present in $62 \%$ of all patients (in $50 \%$ of patients without spasticity and in $100 \%$ of those with spasticity) and was mild in $38 \%$, moderate in $33 \%$, and severe in $29 \% .96 \%$ of the weak patients had hemiparesis, $4 \%$ were tetraparetic. The mere presence of spasticity did not correlate with the intensity of paresis $(P=0.2)$. On the contrary, when accounting for the degree of spasticity patients with higher MAS scores at second follow-up had moderate or severe paresis already at the first examination $(P=0.02)$.

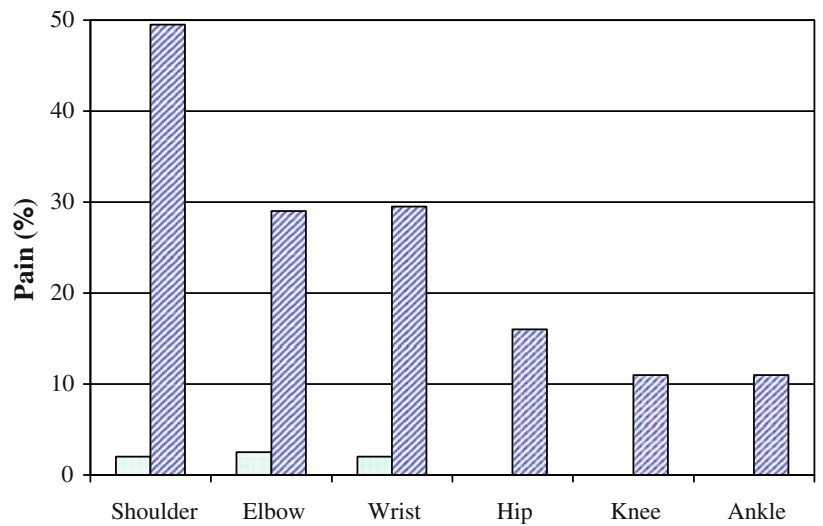

Fig. 4 Frequency and distribution of pain in patients with and without spasticity at second follow-up. Dotted bars mean patients without spasticity (MAS $=0$ ), hatched bars show percent of patients with MAS 1-4 
Median Barthel Index was 95 (45-100) at second follow-up. Patients with spasticity had significantly lower values than patients without $(P=0.035)$. Placement in a nursing home correlated well with the degree of spasticity: $31 \%$ of patients with MAS $2-4$, but only $13 \%$ with MAS $0-1+(P<0.05)$ lived in a facility at second follow-up.

The EQ-5D-index sum score was median 74.6 (range 20-100). Patients without spasticity had a median of 80.6 points, while the score in patients with spasticity was median $63.3(P=0.07)$.

Prognostic factors in the development of spasticity (Table 2)

Early moderate increased muscle tone predicted spasticity at follow-up: MAS of 2 in at least one joint within the first 2 weeks after stroke was only found in patients who had spasticity at the second follow-up (one patient with MAS $=1$ and four patients with MAS $\geq 2$ ). All patients with severe spasticity (MAS $\geq 3, n=8$ ) at second followup had a MAS of two or higher in at least one joint up to the sixth week after stroke $(P=0.01)$. Patients with spasticity at second follow-up had involvement of median 3.5 joints, while patients with eventual recovery had median two joints affected.

Patients without paresis at the first or second follow-up never developed spasticity. Severity of paresis at the second follow-up was significantly correlated with degree of spasticity $(P=0.02)$. Presence of hemiparesis correlated well with spasticity at first $(P=0.02)$ and second $(P=0.005)$ follow-up. Lower Barthel Index at baseline predicted development of more severe spasticity at final follow-up $(P=0.002)$. None of the baseline factors such as age, sex, location, or type of stroke or smoking history was significantly associated with the development of spasticity in this sample.

Ten patients with initial increase of muscle tone were free from spasticity at the second follow-up. In nine of them only the arm and a median of two joints were affected with low degrees of spasticity (MAS $=1$ ), while only one patient with initial hemispasticity had eventual

Table 2 Risk factors for development of permanent spasticity

\begin{tabular}{lc}
\hline Feature & $P$ value \\
\hline Any paresis in affected limb & $<0.001$ \\
More severe paresis at median 16 weeks & 0.02 \\
MAS $\geq 2$ in at least one joint within median 6 weeks & 0.01 \\
after stroke & \\
More than two joints affected by increased muscle tone & 0.002 \\
Hemispasticity within median 6 weeks after stroke & 0.01 \\
Lower Barthel Index at baseline & 0.002 \\
\hline
\end{tabular}

normalisation of muscle tone. No difference in age, sex, stroke localisation, smoking history, and Barthel Index at baseline was found between patients with sustained spasticity and those eventually recovered.

The typical patient with high risk for permanent spasticity showed hemispasticity with emphasis on the arm, more than two joints affected, and MAS scores of 2 or higher up to first follow-up (Table 2).

\section{Discussion}

The strength of this prospective observational study is the high quality of data. The same investigator assessed all patients consecutively, and therefore no interrater variability needs to be considered. Twenty-three patients experienced increased muscle tone within the first 2 weeks following stroke, and eight of them already had a MAS of 2 . Like the other studies we found the highest incidence of spasticity affecting the joints of the arm [11, 14]. Patients with equal or greater MAS 2 at second follow-up were affected by concomitant significantly lower Barthel Index scores, lower quality of life, and more pain. Pain developed within the first 12 weeks after stroke and nearly exclusively emerged in patients with spastic increase of muscle tone.

As described by Sommerfeld et al. [14] we found spasticity in patients at second follow-up who had no spastic muscle tone initially, as well as patients with normal muscle tone at the final assessment who were initially spastic (Fig. 2). Increased muscle tone affecting three or more joints and MAS of 2 or higher in one of the affected joints at baseline or within the first 6 weeks following stroke were associated with severe disabling spasticity at second follow-up. The degree of paresis at the second follow-up was closely related to the degree of spasticity. A lower Barthel Index at baseline predicted higher spasticity at second follow-up, which was also reported by Lundstrom et al. [11]. Other early risk-factors indicating later development of spasticity were not identified in this study.

Until now only a few studies have dealt with the temporal evolution of spasticity after stroke, and most of them surveyed subjects only once and only months after stroke. Several early studies investigated small numbers of patients at different single time points after stroke from one to 76 months, respectively. They stated that spasticity was rarely apparent during the first month following stroke but reached its peak 1-3 months after stroke [3, 6, 9, 13, 15]. A spasticity incidence of $39 \%$ was reported at 12 months by Watkins et al. [17]. This study examined only 106/270 patients of the initial sample; maybe this is the reason for the unusually high proportion of spastic subjects in comparison with the numbers encountered in other studies. Sommerfeld et al. [14] assessed their cohort after a mean of 
5 days after stroke and found $21 \%$ of her patients mildly spastic (MAS 1 and 2), while 3 months later 19\% had spasticity. After 18 months Welmer et al. [18] found 19\% spasticity in their sample in a follow-up study. Lundstrom et al. [11] estimated a prevalence of $17 \%$ of any spasticity 1 year after first-ever stroke. Following the definition of disability of the WHO International classification of function, disability and health concept [20], disabling spasticity emerged with a prevalence of $4 \%$ in the Lundstrom sample at 12 months. The present study confirmed the increase in muscle tone within the first days up to 6 weeks after stroke at close follow-up intervals and found similar numbers of patients affected $(24.5 \%)$.

The rationale of antispastic treatment has changed over the last 20 years. Dietz noted that therapeutic options are limited in spastic movement disorders and leave the doctor somewhat resourceless [4]. Because the increased stiffness of a muscle to stretch results from changes in connective tissue, reduced contractility of muscle fibres, and subclinical contractures due to a loss of sarcomeres, antispastic medication directed against exaggerated reflexes and increased tone will fail to produce functionally relevant improvement of the disturbed movement [5]. Physiotherapy with focus on training of residual motor function, relearning, and activation is the most promising intervention to gain function and to prevent secondary complications $[6,16]$. Medical antispastic interventions may reduce muscle tone and painful spasms in the non-ambulatory patient and thereby improve hand or groin hygiene, dressing hampered by abnormal limb posture, wheelchair seating and transferring. Prevention of pressure sores and heterotopic calcification is vital.

If the decision on physiotherapeutic or pharmaceutic antispastic treatment is reached in the individual patient, the present study advocates early treatment and helps to identify the patient group at highest risk for severe future spasticity. Supportive treatment of spasticity increasingly relies on injection of botulinum toxin into spastic muscles [19]. A prospective, placebo controlled trial will follow the present study to assess the effect of early intervention with botulinum toxin on development of later spasticity, physiotherapeutic training and quality of life in these at-risk post-stroke patients.

Acknowledgment The study was supported by a grant of Stiftung Deutsche Schlaganfall Hilfe. J.S. received an unrestricted travel grant from Allergan. The company has no influence on collection and evaluation of the data or publication. The authors do not have commercial interest relevant to the subject of the manuscript.

Open Access This article is distributed under the terms of the Creative Commons Attribution Noncommercial License which permits any noncommercial use, distribution, and reproduction in any medium, provided the original author(s) and source are credited.

\section{References}

1. Anonymus (1990) EuroQol—a new facility for the measurement of health-related quality of life. The EuroQol group. Health Policy 16:199-208

2. Bohannon RW, Smith MB (1987) Interrater reliability of a modified Ashworth scale of muscle spasticity. Phys Ther 67:206-207

3. Crone C, Johnsen LL, Biering-Sorensen F, Nielsen JB (2003) Appearance of reciprocal facilitation of ankle extensors from ankle flexors in patients with stroke or spinal cord injury. Brain 126:495-507

4. Dietz V (2003) Spastic movement disorder: what is the impact of research on clinical practice? J Neurol Neurosurg Psychiatr 74:820-821

5. Dietz V, Sinkjaer T (2007) Spastic movement disorder: impaired reflex function and altered muscle mechanics. Lancet Neurol 6:725-733

6. Fellows SJ, Ross HF, Thilmann AF (1993) The limitations of the tendon jerk as a marker of pathological stretch reflex activity in human spasticity. J Neurol Neurosurg Psychiatr 56:531-537

7. Hinz A, Klaiberg A, Brähler E, König HH (2006) Der Lebensqualitätsfragebogen EQ-5D: Modelle und Normwerte für die Allgemeinbevölkerung. Psychother Psychol Med 56:42-48

8. Hufschmidt A, Mauritz KH (1985) Chronic transformation of muscle in spasticity: a peripheral contribution to increased tone. $\mathrm{J}$ Neurol Neurosurg Psychiatr 48:676-685

9. Ju MS, Chen JJ, Lee HM, Lin TS, Lin CC, Huang YZ (2000) Time-course analysis of stretch reflexes in hemiparetic subjects using an on-line spasticity measurement system. J Electromyogr Kinesiol 10:1-14

10. Lieber RL, Steinman S, Barash IA, Chambers H (2004) Structural and functional changes in spastic skeletal muscle. Muscle Nerve 29:615-627

11. Lundstrom E, Terent A, Borg J (2008) Prevalence of disabling spasticity 1 year after first-ever stroke. Eur J Neurol 15:533-539

12. Mahoney FI, Barthel DW (1965) Functional evaluation: The Barthel Index. Md State Med J 14:61-65

13. O'Dwyer NJ, Ada L, Neilson PD (1996) Spasticity and muscle contracture following stroke. Brain 119:1737-1749

14. Sommerfeld DK, Eek EU, Svensson AK, Holmqvist LW, von Arbin MH (2004) Spasticity after stroke: its occurrence and association with motor impairments and activity limitations. Stroke 35:134-139

15. Thilmann AF, Fellows SJ, Garms E (1991) The mechanism of spastic muscle hypertonus. Variation in reflex gain over the time course of spasticity. Brain 114:233-244

16. Wade DT, Hewer RL (1987) Functional abilities after stroke: measurement, natural history and prognosis. J Neurol Neurosurg Psychiatr 50:177-182

17. Watkins CL, Leathley MJ, Gregson JM, Moore AP, Smith TL, Sharma AK (2002) Prevalence of spasticity post stroke. Clin Rehabil 16:515-522

18. Welmer AK, von Arbin AM, Widen HL, Sommerfeld DK (2006) Spasticity and its association with functioning and health-related quality of life 18 months after stroke. Cerebrovasc Dis 21:247-253

19. Wissel J, Ward AB, Erztgaard P, Bensmail D, Hecht MJ, Lejeune TM, Schnider P, Altavista MC, Cavazza S, Deltombe T, Duarte E, Geurts AC, Gracies JM, Haboubi NH, Juan FJ, Kasch H, Katterer C, Kirazli Y, Manganotti P, Parman Y, PaternostroSluga T, Petropoulou K, Prempeh R, Rousseaux M, Slawek J, Tieranta N (2009) European consensus table on the use of botulinum toxin type A in adult spasticity. J Rehabil Med 41:13-25

20. World Health Organization (2009) http://www.who.int/classification/icf/en. Last access 19.11.2009

21. Young RR (1994) Spasticity: a review. Neurology 44:12-20 